disease have such a poor prognosis that the pregnancy should be terminated and appropriate treatment started.

Patients found to have a breast carcinoma during lactation should have lactation suppressed by means other than stilboestrol and the carcinoma treated in the usual way.

While the overall survival of the subsequent pregnancy group was not significantly worse than that of matched controls, half of the stage II and all of the stage III patients were dead within seven years of the start of pregnancy.

Ultimately, despite the results and conclusions of this and other reports, treatment in this very complex situation will have to be tailored to the individual patient. What is considered to be the best treatment for the patient by the clinicians may well not be accepted by the patient, and her wishes should not be ignored.

We thank Dr M V Peters and E and S Livingstone Ltd for giving permission to reproduce the findings of Dr Peters (figs 2 and 3). We also thank Miss Sheila Hull for help with the statistical analysis, Dr M P Cole for helpful advice, the medical illustration department, and Mrs Hurst for typing the manuscript.

\section{References}

${ }^{1}$ Holleb, A I, and Farrow, J H, Surgery, Gynecology and Obstetrics, 1962, $115,65$.

${ }^{2}$ Peters, M V, Radiology, 1962, 78, 58.

${ }^{3}$ Peters, M V, Prognostic Factors in Breast Cancer, p 65. London \& Edinburgh, E and S Livingstone Ltd, 1968.

1 Peto, R, et al, British fournal of Cancer, 1977, 35, 1 .

Classification of Malignant Tumours. Geneva, UICC, 1968.

${ }^{6}$ White, T T, American fournal of Obstetrics and Gynecology, 1955, 69, 1277.

- White, T T, Surgery, Gynecology and Obstetrics, 1955, 100, 661.

Montgomery, T L, American fournal of Obstetrics and Gynecology, 1961, $81,926$.

(Accepted 20 October 1977)

\title{
Defective blood glucose counter-regulation in diabetics is a selective form of autonomic neuropathy
}

\author{
L V CAMPBELL, E W KRAEGEN, L LAZARUS
}

\section{Background}

Some data on the mechanism of glucoregulation in hypoglycaemia have been gained from using the insulin tolerance test. This test $(0 \cdot 1-0 \cdot 6 \mathrm{U} / \mathrm{kg}$ neutral insulin by intravenous bolus) produces a rapid, inevitable hypoglycaemia in both normal subjects and diabetics. This evokes a standard stress response with release of catecholamines, glucagon, cortisol, growth hormone, and prolactin. ${ }^{1}$ The release of growth hormone and cortisol is not essential in immediate restoration of blood glucose after hypoglycaemia, ${ }^{2}$ although chronic deficiency of either can cause hypoglycaemia. ${ }^{3}$ In patients under sympathetic blockade, ${ }^{4}$ with cervical cord lesions, ${ }^{5}$ and after adrenalectomy ${ }^{6}$ the sympathoadrenal system does not affect blood glucose restoration during insulin hypoglycaemia. In these patients the glucagon response was also unaffected by the sympathoadrenal system.

Other conflicting data suggest that catecholamines do contribute to restoration of blood glucose during hypoglycaemia, ${ }^{7}$ 8 although their major role probably lies in mobilising alternate substrate for energy production. ${ }^{9}$ In mild hypoglycaemia, however, the blood glucose concentration is restored without adrenaline release. ${ }^{10}$ Thus the release of glucagon is the most essential means of hypoglycaemia counter-regulation. There is evidence from studies of the effects of vagotomy ${ }^{11}$ and atropine $^{12}{ }^{13}$ that an intact vagus is necessary for release of glucagon to offset impending hypoglycaemia. This is consistent with the reports of parasympathetic innervation of the $\alpha$-cell ${ }^{14}{ }^{15}$ and of the efficacy of acetylcholine in the direct stimulation of glucagon release. ${ }^{16}{ }^{17}$ A low blood glucose has been shown to be a direct stimulus to the $\alpha$-cell in vitro when the glucose concentration in the medium is very low ${ }^{18}{ }^{19}$; this response can be suppressed by the presence of non-esterified fatty acid concentrations a 
little above normal." 0 Thus the vagal stimulated release of glucagon is the more important counter-regulatory response to impending hypoglycaemia in normal man.

\section{Evidence}

We designed our studies to assess counter-regulation in a more physiological manner than is possible using the insulin tolerance test. Figure 1 shows the responses that we reported ${ }^{21}$ in fourteen controls and seven insulin-requiring diabetics during low-dose insulin infusion. The normal group consisted of 12 men and 2 women with a mean age of $22 \pm$ SE 1 year. There were four men and three women in the diabetic group (mean

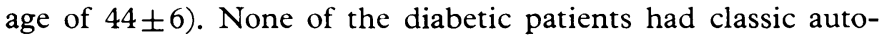
nomic neuropathy-that is, postural hypotension, impotence, bowel or bladder disturbances, hypoglycaemic unawareness, or sweating disturbance. Their known duration of diabetes was from four to 16 years. Three had retinopathy and peripheral neuropathy. All but one had had insulin treatment.

All studies started at 0800 and the diabetics had received their last routine subcutaneous insulin injection at least 24 hours beforehand. The insulin rate of $2 \cdot 4 \mathrm{U} / \mathrm{h}$ was chosen because the mean circulating insulin concentration produced in the controls $(40 \mu \mathrm{U} / \mathrm{ml})$ was within the physiological range. Samples for plasma cortisol, growth hormone, and glucagon were usually collected at 20-minute intervals during the studies. The radioimmunoassay of glucagon was performed using Bloom's Cterminal reacting antibody and a charcoal separation technique.

In the controls, after an initial fall, there was a plateau in blood glucose concentration at $2 \cdot 8 \pm 0 \cdot 2 \mathrm{mmol} / 1(50 \pm 3 \mathrm{mg} /$ $100 \mathrm{ml}$ ). The counter-regulatory response prevented clinical hypoglycaemia, thus preventing a non-specific "stress response" that could mask the more physiological changes of counter-
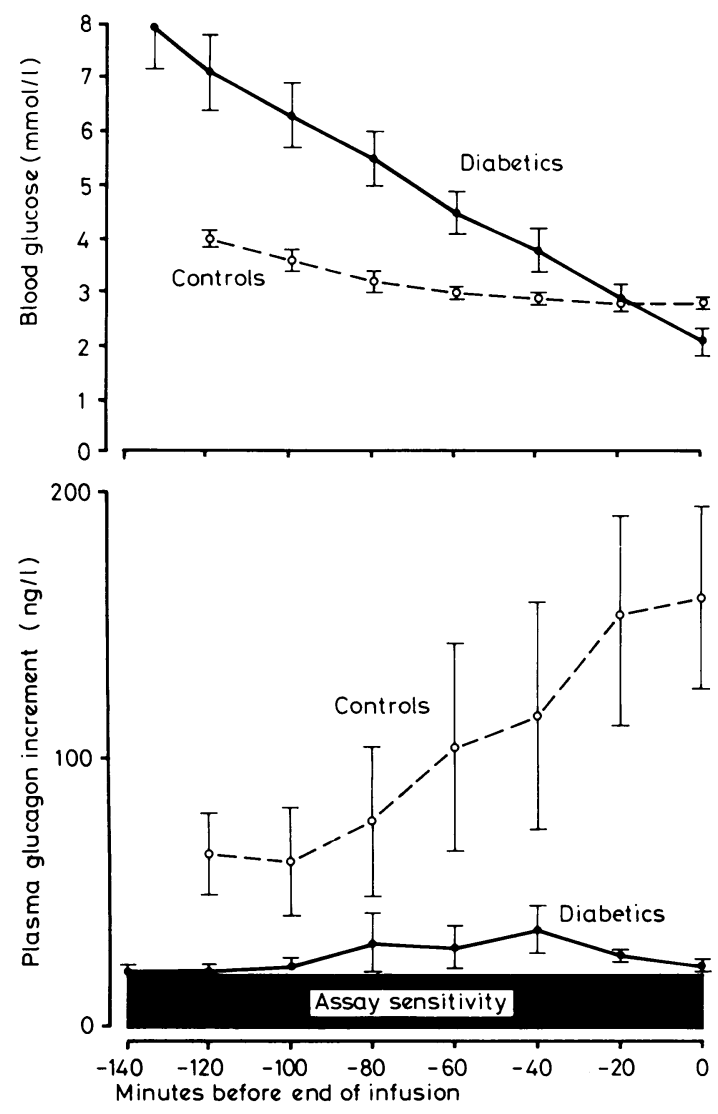

FIG 1-Mean blood glucose levels and glucagon increments in seven diabetic and 14 controls during intravenous infusion of neutral insulin $2 \cdot 4 \mathrm{U} / \mathrm{h}$.
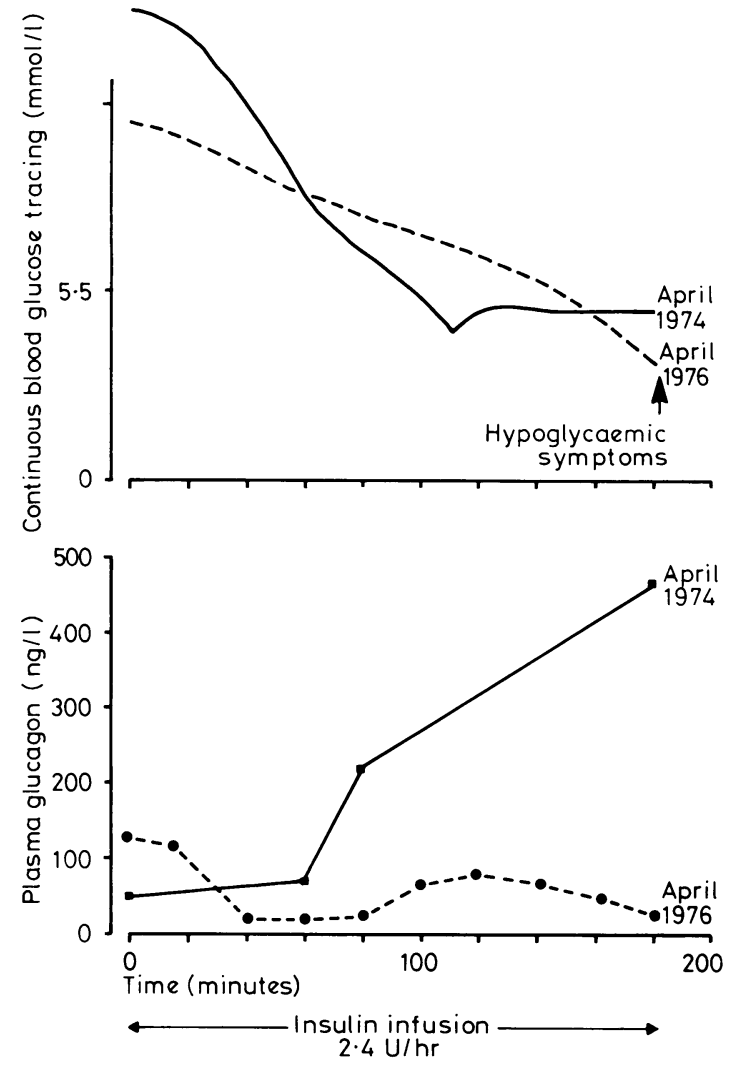

FIG 2-Blood glucose and plasma glucagon responses to lowdose infusion in two studies at a two-year interval.

regulation. As discussed earlier, with a small decrease in blood glucose catecholamine release is unlikely to be of major importance in glucoregulation, and the vagal release of glucagon is essential. The glucagon increment accompanying the plateau in blood glucose in the controls $(135 \pm 54 \mathrm{ng} / \mathrm{l})$ is shown in fig 1 .

In contrast, in the diabetic group, the blood glucose concentration continued to fall during insulin infusion, and, as no rise in glucagon occurred, all became hypoglycaemic (sweating, tachycardia, and subjective symptoms) at a mean blood glucose concentration of $2 \pm 0.3 \mathrm{mmol} / 1(36 \pm 5 \mathrm{mg} / 100 \mathrm{ml})$. The increments in plasma cortisol at the end of the infusion did not differ significantly at the end of the infusion in the two groups (controls: $193 \pm 83 \mathrm{nmol} / 1$; diabetics: $166 \pm 55 \mathrm{nmol} / 1, \mathrm{P}>0.05$ ). Similarly, there was no significant difference between the growth hormone increments at the end of the infusion (controls: $28 \pm 8 \mathrm{mU} / 1$; diabetics: $10 \pm 3 \mathrm{mU} / 1, \mathrm{P}>0.05)$.

As the vagal release of glucagon was absent in these patients, we also measured their glucagon response to direct stimulation of the $\alpha$-cell by an infusion of arginine monochloride $(0 \cdot 25 \mathrm{gm} / \mathrm{kg}$ over 20 minutes). The diabetics had a peak glucagon response $(183 \pm 38 \mathrm{ng} / \mathrm{l})$ significantly greater than the controls $(105 \pm 26$ $\mathrm{ng} / \mathrm{l})$ as has been reported in other series. ${ }^{22}$ The loss of the normal glucagon response to hypoglycaemia with the maintenance of glucagon release during direct stimulation by arginine has also been reported in sheep after denervation of the pancreas by autotransplantation. ${ }^{23}$ Thus, insulin-requiring diabetics may develop a selective autonomic neuropathy, affecting vagal release of glucagon, despite the absence of overt autonomic neuropathy. Islet transplantation in man would result in a similar glucagon unresponsiveness to hypoglycaemia because of the lack of innervation of the donor tissue.

Other groups reporting the absent glucagon response in diabetics during the insulin tolerance test concluded that it was due to an intrinsic $\alpha$-cell defect of diabetes. ${ }^{24}{ }^{25} \mathrm{We}$ dispute this, as the defect is not invariable in insulin-requiring diabetics 2827 and one patient acquired it during the first two years of insulin treatment. He was a 22-year-old man and had had known 
diabetes mellitus for two years when first tested. On both occasions there was no neuropathy or retinopathy. On the first occasion the blood glucose concentration fell until a sustained rise in glucagon occurred and there was a plateau in blood glucose (fig 2). On the second occasion the blood glucose concentration fell until the patient became hypoglycaemic and no sustained rise in glucagon occurred (fig 2). Nevertheless, the glucagon response to arginine infusion was maintained (peak increment $185 \mathrm{ng} / \mathrm{l}$ ). This suggests that the impairment in glucoseregulation is acquired after the onset of diabetes mellitus. The development of a defect in the $x$-cell glucoreceptor would not explain the loss of glucagon response which, in these cases, depends on autonomic control by a glucoreceptor in the central nervous system.

A recent study on diabetic patients with and without gross clinical autonomic neuropathy is consistent with our hypothesis." All "neuropathic" patients showed hypoglycaemic unresponsiveness of glucagon. In a group of eight "nonneuropathic" patients, however, three also had the same defects in glucagon release as the neuropathic. Also the non-neuropathic group had, as a whole, a significantly lower glucagon response to hypoglycaemia than the controls $(P<0.05)$. They had had diabetes for a mean of eight years compared with 16 years in those with gross neuropathy. Thus we believe the nonneuropathic group contained three patients with selective neuropathy affecting glucagon release. In another study" diabetics with defective glucagon release during the insulin tolerance test received adrenaline infusions in the belief that unresponsiveness of the $\alpha$-cell to catecholamines could be responsible for the defect. On the contrary, the diabetics' glucagon response was significantly greater $(P<0.005)$ than that of the controls (half of whom did not respond). This type of response would be consistent with denervation sensitivity ${ }^{28}$ suggesting that pancreatic sympathetic denervation may also be present. This study also reported the same urinary adrenaline excretion in these diabetics as in controls over two hours during the insulin tolerance test. Nevertheless, as the diabetics were hypoglycaemic for a much longer time than the controls a prolonged inadequate adrenaline release may still have occurred. Plasma catecholamine measurements will resolve the question of adequacy of catecholamine release in the diabetics with impaired glucagon release and their role in the counter-regulatory defect.

Thus we suggest that selective defects of autonomic neuropathy may occur more often and at an earlier stage in diabetes than the classical syndrome of autonomic neuropathy previously described. This is already recognised in the cardiovascular system ${ }^{29}$ and in the eye. ${ }^{30}$ We propose that glucagon unresponsiveness to impending hypoglycaemia is another such defect and the accompanying failure of the glucoregulation is its clinical manifestation.

\section{References}

${ }^{1}$ Ajilouni, K, Sill, A J, and Hagen, T C, Diabetes, 1976, 25, suppl 1, 351

${ }^{2}$ Feldman, J M, Plonk, J W, and Bivens, C $\mathrm{H}$, Hormone and Metabolic Research, 1975, 7, 378.

${ }^{3}$ De Bodo, R C, et al, Recent Progress in Hormone Research, ed G Pincus. London, Academic Press, 1963.

${ }^{4}$ Walter, R M, et al, fournal of Clinical Investigation, 1974, 54, 1214.

${ }^{5}$ Palmer, J P, and Ensinck, J W, Diabetes, 1974, 23, suppl 1, 342.

${ }^{6}$ Ginsberg, J, and Paton, A, Lancet, 1956, 2, 491.

Garber, A J, et al, fournal of Clinical Investigation, 1976, 58, 7.

${ }^{8}$ Gerich, J, et al, Diabetes, 1977, 26, suppl 1, 384.

${ }^{9}$ Christensen, N J, Alberti, K G M M, and Brandsborg, O, European Fournal of Clinical Investigation, $1975, \mathbf{5}, 415$.

10 Wallace, J M, and Harlan, W R, American fournal of Medicine, 1965, 38, 531

11 Russell, R C G, Thomson, J P S, and Bloom, S R, British fournal of Surgery, 1974, 61, 821.

${ }_{12}$ Bloom, S R, Vaughan, N J A, and Russell, R C G, Lancet, 1974, 2, 546.

13 Vaughan, N J A, et al, Experientia, 1973, 29, 805.

${ }^{14}$ Esterhuizen, A C, Spriggs, T L B, and Lever, J D, Diabetes, 1969, 17, 33.

15 Renold, A E, Diabetes, 1971, 21, suppl 2, 619.

${ }^{16}$ Iversen, J, Diabetes, 1973, 22, 381.

1. Loubatieres, A-L, Loubatieres, M M-M, and Chapal, J, Diabetelogia, $1975,11,360$.

$1 *$ Weir, G C, Knowlton, S D, and Martin, D B, fournal of Clinical Investigation, 1974, 54, 1403.

${ }^{19}$ Iversen, J, fournal of Clinical Investigation, 1971, 50, 2123.

${ }^{20}$ Edwards, J C, and Taylor, K W, Biochimica et Biophysica Acta, 1970, 215, 310

${ }^{21}$ Campbell, L V, et al, in Current Topics in Diabetes Research, ed J S Bajaj, p 35. Amsterdam, Excerpta Medica, 1976.

22. Unger, R H, et al, fournal of Clinical Investigation, 1970, 49, 837.

${ }^{23}$ Beaven, D W, et al, in Current Topics in Diabetes Research, ed J S Bajaj, p 34. Amsterdam, Excerpta Medica, 1976.

24 Gerich, J E W, et al, Science, 1973, 182, 171

${ }_{25}$ Benson, J W, et al, fournal of Clinical Endocrinology and Metabolism, 1977, 44, 459.

${ }^{26}$ Reynolds, C, et al, Diabetes, 1977, 26, 36.

27 Maher, T D, et al, Diabetes, 1977, 26, 196

${ }^{2 *}$ Kuntz, A, The Autonomic Nervous System. Philadelphia, Lea and Febiger, 1953.

${ }^{29}$ Gundersen, H J G, and Neubauer, B, Diabetalogia, 1977, 13, 137.

30) Gundersen, H J G, Ophthalmologica, 1976, 172, 62.

(Accepted 26 October 1977)

\section{What was "sweating sickness" in mediaeval times?}

The sweating disease of the "English sweats" was the name given to a series of epidemics that first appeared in England in 1485 and disappeared equally suddenly after 1551 . The disease attacked particularly the upper classes and had a high mortality. Outbreaks also occurred on the Continent. Opinions are divided as to what it was but the general consensus is that it was a form of influenza. John Caius published A Boke or Counseill against the Sweate or Sweatying Sicknesse.

Is there any danger for men working in scrap metal yards from handling lead, where the only process apart from the handling is cropping-cutting lead with sharp shears into small sections for handling?

Handling clean metallic lead in scrap metal yards should not cause any problem as dust is unlikely to arise. Nevertheless, the surface coating of oxide even from clean lead may get on the hands, so that workmen must wash before eating. Most scrap lead, however, tends to be dirty and have a coating of oxide or other compounds of lead depending on what chemicals it may have been in contact with. In such cases the handling may well raise a dust, which may be absorbed in toxic amounts. Battery scrap consists of lead grids that have been filled with a lead oxide paste. It is notoriously dusty, and for this reason many scrap merchants avoid handling it. Dampening of this scrap is essential for safe handling and good housekeeping is necessary to prevent toxic effects. Cutting lead into small sections with sharp shears should not produce any hazards unless the lead is old and dirty, when the risks described above could create a problem.

\section{Are the red smoke emissions from a steelworks hazardous?}

Red smoke emissions from a steelworks consist mainly of iron oxide with a small proportion of calcium compounds and negligible traces of other metallic oxides. Iron oxide is an inert dust, and the threshold limit value (TLV), which is the time-weighted average concentration for a normal eight-hour work day or a 40-hour work week to which nearly all workers may be repeatedly exposed day after day without adverse effect, is $10 \mathrm{mg} / \mathrm{m}^{3} .^{1}$ In the neighbourhood of a steelworks dilution of the emissions is such that exposure levels will be only a small fraction of the TLV. There is, therefore, no health hazard, though the particulate iron oxide may prove a nuisance, especially to people living in the area of deposition. A special study in and around two integrated steelworks in South Wales confirmed the absence of a health hazard. ${ }^{23}$

${ }^{1}$ Health and Safety Executive, Threshold Limit Values for 1976, guidance note

${ }_{3}^{2}$ Warner, C G, et al, Annals of Occupational Hygiene, 1969, 12, 151. 